Review

\title{
Carrier Screening for Cystic Fibrosis: Past, Present and Future
}

Myrto Poulou $^{1, *}$, Maria Tzetis ${ }^{1}$

Department of Medical Genetics, Medical School, National and Kapodistrian University of Athens, Greece; E-Mail:mrpoulou@med.uoa.gr; mtzetis@med.uoa.gr

* Correspondence: Myrto Poulou,mrpoulou@med.uoa.gr

Academic Editors: Joanne Traeger-Synodinos and François Rousseau

\section{OBM Genetics}

2017, volume 1 , issue 4

doi:10.21926/obm.genet.1704010
Received: July 31, 2017

Accepted: October 24, 2017

Published: November 03, 2017

\begin{abstract}
Cystic Fibrosis (CF) is one of the commonest autosomal recessive genetic diseases that show a high carrier frequency amongst Caucasian populations. Although there has been tremendous progress in the available therapies, compared to the past, the disease is still associated with significant morbidity and mortality. Because of the severe clinical manifestations and the shortened life expectancy of patients, population based carrier screening, to identify heterozygous carrier couples at risk of having affected children, has been recommended. We review the history of population based carrier screening for CF, focusing on the screening guidelines, the current requirements and the difficulties of implementation, considering especially the heterogeneity of CF-causing mutations.
\end{abstract}

\section{Keywords:}

Cystic fibrosis; population based carrier screening; mutation analysis; guidelines for screening; CFTR gene

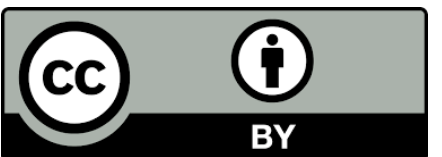

(C) 2017 by the author. This is an open access article distributed under the conditions of the Creative Commons by Attribution License, which permits unrestricted use, distribution, and reproduction in any medium or format, provided the original work is correctly cited. 


\section{Cystic fibrosis facts}

Since the discovery of the DNA double helix, 64 years ago, there has been a tremendous progress in identifying disease causing genes, especially for the monogenic disorders. For cystic fibrosis (CF), the responsible gene, cystic fibrosis transmembrane conductase regulator - CFTR, was identified and its coding regions were sequenced in 1989 [1, 2]. Mutation analysis was offered to patients fulfilling the criteria for cystic fibrosis diagnosis and that led to the identification of disease causing mutations and establishment of mutation frequencies to the tested ethnic groups [3-6]. From these early years of the "mutation-detection era", there was the aspiration of offering population carrier screening to identify carrier-couples at risk of having a child with cystic fibrosis [7-9].

CF is one of the commonest autosomal recessive disorders in Caucasians, with a carrier frequency of 1 in 25-30 and birth prevalence of approximately 1 in 2300. Cystic fibrosis is one of the most common, inherited life-shortening diseases of childhood. It affects multiple organ systems in the body mainly the respiratory and the gastrointestinal system. The severity of the clinical presentations varies greatly among patients from multi-organ involvement in the most severe form, which presents in the neonatal period to early childhood, to single organ manifestations, such as recurrent pancreatitis or male infertility due to congenital bilateral absence of the vas deferens (CBAVD) that could manifest later in adult life [10,11]. These discrepancies are largely due to the different mutations the patients bear but other reasons have been recognized to influence the outcome such as mutations in modifier genes, environmental factors and even stochastic events [12-14].

The disorder has been reported in other ethnic groups aside from Caucasians, but it presents with lower birth prevalence. CF is considered uncommon in Africa and Asia although in most cases, data on birth prevalence are not available. The lowest reported frequency is in Japan with an incidence of 1 in 350000 live births [15-17].

CF occurs due to mutations in the CFTR gene, located in the long arm of chromosome 7 (7q31.2). The CFTR mutation database, a database that was initiated in 1989 by the Cystic Fibrosis Genetic Analysis Consortium to increase and facilitate communications among CF researchers and is devoted to the recording of CFTR gene mutations for the international cystic fibrosis genetics research community, currently lists almost 2000 mutations, of which the vast majority are missense [18]. The CFTR mutation spectrum exhibits a high degree of heterogeneity; with some mutations being specific in some ethnic groups and others being extremely rare to the degree to be considered private. The mutation heterogeneity in Europe increases as we move from the more homogeneous, population wise, north to the less homogeneous south of the continent [19].

However the commonest mutation in almost all ethnic groups is p.Phe508del (legacy name F508del, $\Delta \mathrm{F} 508$ ) reaching almost $100 \%$ in the isolated Faroe Islands of Denmark and $25 \%$ in Turkey [19]. Besides p.Phe508del there are at least 3 mutations that are common in all ethnic groups, with varying frequencies, namely p.Gly542X (legacy name G542X), p.Asn1303Lys (legacy name N1303K) and p.Gly551Asp (legacy name G551D). The great mutational heterogeneity in CF poses serious issues to the implementation of a general population screening program. In order to achieve maximum benefits of such programs, the mutations and their frequencies in the screened populations should be known beforehand [19-21]. 


\section{Definition of carrier screening}

"Screening is the systematic application of a test or enquiry to identify individuals at sufficient risk of a specific disorder to warrant further investigation or direct preventive action, amongst persons who have not sought medical attention on account of symptoms of that disorder"[22]. In order to judge if a disorder is suitable for screening, specific criteria should be fulfilled. To name some, the condition should be well defined and the prevalence should be known, the program should promote equity and access to screening for the entire target population, the program evaluation should be planned from the outset and the overall benefits of screening should outweigh the possible harm, which refers mainly to psychological impact of being informed of a carrier status [23-28].

Genetic screening for cystic fibrosis can be performed in two different settings, achieving different goals: a) Newborn screening, aiming at recognizing disease state and b) Carrier screening, aiming at recognizing unaffected individuals at risk of having an offspring with $\mathrm{CF}$, the latter being the scope of this paper [29].

At this point a clear distinction should be made between carrier testing and carrier screening. Carrier testing refers to detecting CF-causing mutations in individuals who have an a-priori increased risk of being carriers, due to family history of CF or personal history of a CFTR related disease (CFTR-RD). A CFTR-RD is "a clinical entity associated with CFTR dysfunction that does not fulfill diagnostic criteria for CF" [11]. If there is a family history, the mutation detection protocol used should include the mutations present in the family.

Carrier screening on the other hand refers to detecting CF-causing mutations in individuals with no a-priori increased risk of being carriers (general population) or individuals whose partners are not CF carriers or CF patients, and therefore are not at an increased risk of having an offspring with cystic fibrosis. Carrier screening should be voluntary and performed only as an informed decision. Therefore carrier screening of minors or individuals unable to provide informed consent should be discouraged. Pre- and post-testing counseling is essential, so that the individuals understand the procedure, the meaning of a positive test result and the implications for a subsequent pregnancy if the partner is also tested positive as well as the meaning of a negative test result and the residual risk of being a carrier.

The best time to perform carrier screening is in the preconception period, when the couple is planning a pregnancy. At this time all reproductive options are open for the couples that test positive, including prenatal diagnosis early in the pregnancy, in vitro fertilization (IVF) followed by pre-implantation genetic diagnosis (PGD) or IVF using donor gametes, adoption and even decision against having children. Often the occurrence of pregnancy is not planned and in such cases carrier screening should be performed, at the earliest time possible. In this case the choices of a carrier couple are limited and anxiety during the test period increases substantially.

There are different strategies of pursuing screening. It can be performed only for one partner, sequentially to both members of the couple reporting the carrier status of each member or simultaneously for both partners, reporting results for the couple as entity. The choice for the approach to be used depends on personal choice, time frame and financial issues. If the decision is made to screen only one partner, then female testing should be preferred as a negative test result offers security in cases of undisclosed non-paternity. In the sequential approach, identified carriers are notified of their carrier status giving opportunity for cascade screening of other members of 
the family at increased risk of being carriers. If screening is performed during an ongoing pregnancy, testing simultaneously both members of the couple is preferred as it is more time effective in relation to the pregnancy. Finally if a pregnancy is achieved using gamete donors, it is essential to counsel the couple that screening for CFTR mutations should be applied to the gamete donors $[21,29,30]$.

\section{Carrier screening: the early years - the first guidelines}

Carrier screening for cystic fibrosis has been possible for almost 25 years, but before it could be implemented there was a great need to investigate parameters such as: who should be tested, which mutations should be included, when was the right time for testing, did the benefits outweigh the possible harm, who and how would inform and counsel the participants and finally who would cover the cost [31-34]. Therefore, although carrier screening was technically feasible since F508del was identified as the most common causative mutation, the first pilot screening programs occurred in the early to mid 90s [35, 36].

After the discovery of the gene, diagnostic laboratories mainly in Europe and the U.S. started offering genetic testing to CF patients in order to identify the causative mutations. The Cystic Fibrosis Genetic Analysis Consortium was formed in order to catalogue the large, and growing, number of disease-causing mutations. The purpose of the Consortium was to increase and facilitate communications among CF researchers who were working on mutation identification in the CFTR gene [37]. This enabled the definition of the mutation spectrum in each distinct population. Before CF mutation screening was available for the general population the first groups that were offered testing, in the early 90s, were relatives of patients and partners of recognized carriers $[38,39]$. Carrier testing was also indicated in cases of couples undergoing IVF due to male infertility and in cases of pregnancy with sonographic echogenic bowel findings during the $2^{\text {nd }}$ trimester $[40,41]$. In the late 90 s carrier screening for CF started being available for the general population and was offered mainly to couples considering having a child or at the early stages of an ongoing pregnancy [35].

Before guidelines for population based cystic fibrosis carrier screening where made available, the choice of which mutations would be included in a screening panel was a decision made by the laboratory offering the test. The common practice was to test for the most common mutation in all ethnic groups p.Phe508del [42], and 5 of the other common mutations (p.Gly542X, p.Asn1303Lys, p.Gly551Asp, p.Arg553X and p.Trp1282X) [35]. In a study published by Grody et al. [43], forty-five US laboratories offering CF carrier testing, were interrogated on the number of mutations covered. The answers varied from 1 mutation to 70 with the median being around 1214 mutations [43].

In 1997, the National Institutes of Health $(\mathrm{NIH})$ recognizing the need for guidelines regarding carrier screening for CF convened a Consesus Conference on Cystic Fibrosis testing. Following that in 2001, a joint statement from the American College of Medical Genetics (ACMG), the American College of Obstetricians and Gynecologists (ACOG) and NIH was released recommending that CFTR mutation testing was to be made available to all pregnant couples, independently of their personal/family history or their ethnicity, and to all couples planning a pregnancy [44].

Specifically the committee recommended that CF carrier screening be offered to non-Jewish Caucasians and Ashkenazi Jews, and made available to other ethnic groups, informing them on the 
detection rates applicable to their ethnic origin. Ideally testing should occur in the preconception period and should be performed either couple based or sequential depending on a) target population (frequency of carriers), b) availability of testing, and c) judgment of the referring practitioner. The recommended mutation panel was pan-ethnic, including variants with allele frequency $\geq 0.1 \%$ in the general US population. All mutations of this frequency were to be included in the recommended panel, regardless of their association with severe or mild disease. The committee proposed a panel of 25 mutations (Table 1) that fulfilled these criteria. Reflex testing of the benign variants p.lle506Val, p.lle507Val, and p.Phe508Cys was suggested for unexpected homozygosity in healthy individuals for the CF-causing mutations p.Phe508del or p.lle507del and for determination of the genotype for the polyT track polymorphism in intron 9 (legacy intron 8), in case of detection of the mild p.Arg117His mutation was suggested. The genotype of the polyT track can vary between 5T, 7T and 9T. Individuals carrying p.Arg117His mutation plus the 5T variant in cis (on the same allele) when combined with a CF causing mutation can develop CF, but individuals with p.Arg117His and the 7T or 9T variant in cis in combination with a CF causing mutation have a highly variable phenotype that can range from no symptoms to mild lung disease $[45,46]$.

The committee recommended against the routine use of an extended mutation panel following a negative testing result using the standard mutation panel for a partner of a positive-tested (carrier) individual (positive/negative couple), the rationale being that it couldn't be available in every testing laboratory, it would have an effect of increasing anxiety and it would provide low additional yield, increasing the detection rate by only a small fraction. However the existence of an expanded mutation panel should be made available to couples requesting it and its use should be considered on a case-by case basis [44].

Table 1. Standard mutation panel recommended in 2001 [44].

\begin{tabular}{|c|c|c|c|c|}
\hline p.Phe508del ${ }^{a}$ & p.lle507del ${ }^{a}$ & p.Gly542X & c.984delT (1078delT) & $\begin{array}{l}c .489+1 G>T \\
(621+1 G>T) \\
\end{array}$ \\
\hline p.Arg553X & p.Arg1162X & p.Asn1303Lys & $\begin{array}{l}\text { c. } 3717+12191 C>T \\
(3849+10 K b \text { T }>C)\end{array}$ & $\begin{array}{l}\text { c. } 1585-1 G>A \\
(1717-1 G>A)\end{array}$ \\
\hline p.Ala455Glu & p.Arg560Thr & p.Gly85Glu & c.2052delA (2184delA) & $\begin{array}{l}\text { c. } 2988+1 G>A \\
(3120+1 G>A)\end{array}$ \\
\hline p.Trp1282X & p.Arg334Trp & p.lle148Thr & c. $2657+5 G>A(2789+5 G>A)$ & $\begin{array}{l}\text { c. } 1766+1 G>A \\
(1898+1 G>A)\end{array}$ \\
\hline p.Arg117His ${ }^{b}$ & p.Arg347Pro & p.Gly551Asp & c.3528delC (3659delC) & $\begin{array}{l}c .579+1 G>T \\
(711+1 G>T)\end{array}$ \\
\hline
\end{tabular}

Reflex tests: p.lle506Val ${ }^{a}$, p.lle507Val ${ }^{a}$, p.Phe508Cys ${ }^{a}, 5 \mathrm{~T} / 7 \mathrm{~T} / 9 \mathrm{~T}^{\mathrm{b}}$

* HGVS nomenclature, in parentheses the legacy nomenclature of the mutation is stated.

\section{Carrier screening: the here and now}

The guidelines issued by ACOG/ACMG/NIH in 2001, were revised in 2004 [47]. The revision aimed to clarify three important points. Firstly, had the observed frequency of any CF mutation changed significantly; which meant that mutations included in the panel present with a frequency 
$<0.1 \%$ now had to be removed and mutations not included in the initial panel with a frequency $\geq 0.1 \%$ had to be added. Secondly it was important to verify that the prevalence of CF mutations in the worldwide general population was as expected, based on predictions made using observed frequencies in CF patients. And lastly the revision aimed at recognizing any consistent and recurring issues arising with interpretation of specific mutations that needed to be addressed.

The conclusions were that mutation c.984delT (legacy name 1078delT) had to be removed since the observed frequency in CF cases was merely $0.03 \%$ (well below the inclusion frequency) and mutation p.lle148Thr also had to be removed since it was found in higher frequency in the general population than in CF cases. That finding indicated that p.lle148Thr was not a CF causing mutation but rather a rare non-disease associated variant. Indeed, extended mutation testing of patients carrying p.lle148Thr showed that the true CF causing mutation was c.3067_3072delATAGTG (legacy name 3199del6) found in cis with p.lle148Thr. Since the frequency of c.3067_3072delATAGTG was considerably lower than $0.1 \%$ it was decided that it should not be included in the screening panel [48].

As mentioned in the consensus document from 2001 [44], p.Arg117His was challenging in interpretation. This mutation is a mild variant, identified in CBAVD patients and should be considered a CF-causing mutation only when it is found in cis with the $5 \mathrm{~T}$ polymorphism. The polyT track genotype (i.e. 5T/7T/9T) should not be reported in the absence of p.Arg117His. Due to the frequency of this mutation, the committee recommended to retain p.Arg117His in the screening panel and emphasized the need for testing the polyT track only as a reflex testing. Currently the updated panel of 23 mutations is recommended by ACOG/ACMG/NIH [47].

In 2010 a European consensus document was published [21] aiming to outline the principles of screening. The characteristics of the screening program, namely the voluntary nature, the accessibility and the pre- and post- counseling were emphasized. The document states that screening should be made available to all couples, ideally in the preconception period and especially discourages direct fetal screening, without prior ascertainment of the parental mutations. This document does not propose a specific mutation panel but instead recommends on adapting the panel that best fits the target population. Since European populations are highly heterogeneic, the mutation panel for each distinct population should include only CF causing mutations that are present in frequencies above $0.5-1 \%$ in the CF patient population from which the individual originates. Recognizing that in the more heterogeneous South of the continent a high detection rate is difficult to be attained, the committee recommends aiming at a minimally a $70 \%$ detection rate to $90 \%$ optimally. These guidelines, as the ones from the ACOG/ACMG/NIH, recommended against gene scanning/sequencing for the initial screen or for the partner of an identified carrier, as this could lead to identification of mutations of unknown significance resulting in inability to pass on accurate information for the couple's risk of having a child suffering from cystic fibrosis [49]. However it advises than whenever possible, partners of carriers should be tested with a more accurate mutation panel.

In 2014 the Human Genetics Society of Australasia, published an updated position statement on population based carrier screening for cystic fibrosis [50]. In this statement the authors also recommend that all couples intending to have children or who are pregnant should be made aware of the availability for CF carrier screening. Based on the population composition of Australasia a recommended panel of 17 mutations, capable of identifying $80 \%$ of carriers was proposed. The panel did not include mutations that are associated with an unclear phenotype or 
lead to atypical disease, therefore p.Arg117His and the polyT polymorphisms were excluded from testing. Extensive sequencing of the negative partner in a positive/negative screened couple was also not recommended, however the identification of a carrier pregnant woman whose partner was unavailable for screening should lead to genetic counseling where one of the issues could be direct testing of the fetus.

Overall, international directives for population based carrier screening in CF that apply today, recommend that all individuals who are planning or are in the early stages of pregnancy should be offered CF carrier screening. The mutation panel used should be specific for the population from which the individual originates and the pre- and post- testing counseling should be offered in order for the individual to recognize the benefits and limitations of each screening approach.

However some national organizations, the Society of Obstetricians and Gynaecologists of Canada (SOGC), the UK National Screening Committee and the National Consultative Ethics Committee for Health and Life Sciences in France, have decided against universal carrier screening and recommend carrier testing to be offered only to individuals that are at an increased risk of an affected child due to ethnic background, personal or family history, or clinical manifestations of this condition in themselves or the pregnancy $[51,52]$.

\section{Carrier screening: what lies ahead?}

Since the first guidelines, regarding population based carrier screening for cystic fibrosis were released, a lot has changed in the context of technological advancements as well as in our knowledge on disease causing mutations [12, 44, 53, 54].

The introduction of Next Generation Sequencing (NGS) platforms has allowed the simultaneous mutation testing for more than a hundred genetic conditions at a comparable cost as when testing mutations in a single gene or a small number of population specific mutations in several genes [5558]. In view of the technological advancements the new era of preconception screening is moving fast towards an Expanded Carrier Screening (ECS) approach. ECS refers to testing for a plethora of genetic diseases; usually the ones with an autosomal recessive pattern of inheritance and it can be applied either by sequencing or genotyping. Sequencing will reveal any variation (single nucleotide variation or small insertion/deletion but not large rearrangements) in the sequenced gene and genotyping will only reveal specific, pre-defined, mutations. In the context of population carrier screening, genotyping may be the best approach as only pathogenic variants or likely pathogenic variants can be included in the analysis.

As we move from the traditional single gene screening to large panels of genes being analyzed, it is very important to set rigorous criteria for the selection of disease causing genes to be included in the panel used. The more the merrier should not be the approach used and specific guidelines indicating the selection criteria have already been published [55, 59]. Cystic Fibrosis is a disease complying with the selection criteria and therefore it should be included in any preconception ECS panel.

An issue that will certainly arise though is which CF mutations should be included. Should we continue proposing the 23 pan-ethnic mutation panel suggested by ACOG/ACMG/NIH [47], should we test for all pathogenic mutations present in the screened population that appear with a frequency even lower to the "gold standard" of $0.1 \%$ or should we screen the whole gene and report only pathogenic / likely pathogenic variants even if they are novel following the "Standards 
and Guidelines for the Interpretation of Sequence Variants: A Joint Consensus Recommendation of the American College of Medical Genetics and Genomics and the Association for Molecular Pathology" [60]. This question has no easy answer and has raised a lot of debate [61, 62] and we believe that the best approach should be custom-made for each distinct population.

In South Europe, Greece and Italy present high genetic heterogeneity for CFTR mutations and the 23 mutation panel reaches a detection rate of less than $80 \%$. For such populations the best approach for screening would be the use of an expanded mutation panel [63]. Our department offers genetic testing to patients as well as genetic screening for cystic fibrosis since 1992. Until now we have tested the majority of Greek patients and more than 20,000 members of the general population. From our data-set (unpublished data - manuscript in preparation) after screening the whole coding sequencing and applying MLPA analysis we have identified 64 mutations with frequencies $\geq 0.1 \%$ and in total 135 disease-causing mutations reaching a detection rate of $95 \%$. These data emphasize the need for applying an extended CFTR screening protocol to a heterogeneous population in order to achieve a high detection rate [64].

A major issue that needs to be resolved involves the economic considerations. Unfortunately the only plausible way to test individuals for cystic fibrosis carrier status is by DNA mutation analysis. The fact that there is no biochemical or hematological test available, like when testing for thalassemias, skyrockets the cost for such programs. It is true that most international guidelines suggest that carrier screening should be made available to all individuals of reproductive age, but the cost currently is covered on a user-pay basis. This abolishes the equity principle of screening, as only those who can afford it will benefit. Although the cost-effectiveness of population based carrier screening for cystic fibrosis has been the issue of many studies [65-69], it is difficult to reach a uniform conclusion.

Implementation of a cystic fibrosis population-based carrier screening program has to overcome many obstacles. It is evident that the decision to include CF carrier screening in the services that the national health system provide should be based on the health economics of each country and the carrier frequency in the tested population.

\section{Acknowledgments}

We would like to thank Dr. Georgia Kakourou for language editing and proofreading of the final manuscript.

\section{Author Contributions}

All authors contributed equally. M.P.: Reviewed the literature and prepared the manuscript. M.T: Reviewed the literature, proofread and approved the manuscript.

\section{Funding Source}

No funding.

\section{Competing Interests}

The authors have declared that no competing interests exists 


\section{References}

1. Riordan JR, Rommens JM, Kerem B, Alon N, Rozmahel R, Grzelczak Z, et al. Identification of the cystic fibrosis gene: cloning and characterization of complementary DNA. Science. 1989;245(4922):1066-73.

2. Rommens JM, lannuzzi MC, Kerem B, Drumm ML, Melmer G, Dean M, et al. Identification of the cystic fibrosis gene: chromosome walking and jumping. Science. 1989;245(4922):1059-65.

3. Coutelle C, Bruckner R, Grade K, Behrens F, Gedschold J, Hein J, et al. Prevalence of cystic fibrosis mutations in the East German population. Human mutation. 1992;1(2):109-12.

4. Claustres M, Gerrard B, Kjellberg P, Desgeorges M, Demaille J, Dean M. Screening for cystic fibrosis mutations in southern France: identification of a frameshift mutation and two missense variations. Human mutation. 1992;1(4):310-3.

5. Fellowes AP, Murphy JM, Wesley AW, Dawson KP, George PM. Molecular screening of cystic fibrosis patients. The New Zealand medical journal. 1991;104(921):415-6.

6. Cutting GR, Curristin SM, Nash E, Rosenstein BJ, Lerer I, Abeliovich D, et al. Analysis of four diverse population groups indicates that a subset of cystic fibrosis mutations occur in common among Caucasians. American journal of human genetics. 1992;50(6):1185-94.

7. Wilfond BS, Fost $\mathrm{N}$. The cystic fibrosis gene: medical and social implications for heterozygote detection. Jama. 1990;263(20):2777-83.

8. Williamson R, Allison ME, Bentley TJ, Lim SM, Watson E, Chapple J, et al. Community attitudes to cystic fibrosis carrier testing in England: a pilot study. Prenatal diagnosis. 1989;9(10):72734.

9. Green JM. Principles and practicalities of carrier screening: attitudes of recent parents. Journal of medical genetics. 1992;29(5):313-9.

10. Bombieri C, Seia M, Castellani C. Genotypes and phenotypes in cystic fibrosis and cystic fibrosis transmembrane regulator-related disorders. Seminars in respiratory and critical care medicine. 2015;36(2):180-93.

11. Bombieri C, Claustres M, De Boeck K, Derichs N, Dodge J, Girodon E, et al. Recommendations for the classification of diseases as CFTR-related disorders. Journal of cystic fibrosis : official journal of the European Cystic Fibrosis Society. 2011;10 Suppl 2:S86-102.

12. Cutting GR. Cystic fibrosis genetics: from molecular understanding to clinical application. Nature reviews Genetics. 2015;16(1):45-56.

13. Zielenski J. Genotype and phenotype in cystic fibrosis. Respiration; international review of thoracic diseases. 2000;67(2):117-33.

14. Mickle JE, Cutting GR. Clinical implications of cystic fibrosis transmembrane conductance regulator mutations. Clinics in chest medicine. 1998;19(3):443-58, v.

15. O'Sullivan BP, Freedman SD. Cystic fibrosis. Lancet. 2009;373(9678):1891-904.

16. Schrijver I, Pique L, Graham S, Pearl M, Cherry A, Kharrazi M. The Spectrum of CFTR Variants in Nonwhite Cystic Fibrosis Patients: Implications for Molecular Diagnostic Testing. The Journal of molecular diagnostics : JMD. 2016;18(1):39-50.

17. Yamashiro Y, Shimizu T, Oguchi S, Shioya T, Nagata S, Ohtsuka Y. The estimated incidence of cystic fibrosis in Japan. Journal of pediatric gastroenterology and nutrition. 1997;24(5):544-7.

18. Cystic Fibrosis Mutation Database Accessed May 2017 [Available from: http://www.genet.sickkids.on.ca. 
19. Bobadilla JL, Macek M, Jr., Fine JP, Farrell PM. Cystic fibrosis: a worldwide analysis of CFTR mutations--correlation with incidence data and application to screening. Human mutation. 2002;19(6):575-606.

20. Bobadilla JL, Farrell MH, Farrell PM. Applying CFTR molecular genetics to facilitate the diagnosis of cystic fibrosis through screening. Advances in pediatrics. 2002;49:131-90.

21. Castellani C, Macek M, Jr., Cassiman JJ, Duff A, Massie J, ten Kate LP, et al. Benchmarks for cystic fibrosis carrier screening: a European consensus document. Journal of cystic fibrosis : official journal of the European Cystic Fibrosis Society. 2010;9(3):165-78.

22. Wald NJ. The definition of screening. Journal of medical screening. 2001;8(1):1.

23. Wilson JM, Jungner YG. [Principles and practice of mass screening for disease]. Boletin de la Oficina Sanitaria Panamericana Pan American Sanitary Bureau. 1968;65(4):281-393.

24. Andermann A, Blancquaert I, Beauchamp S, Dery V. Revisiting Wilson and Jungner in the genomic age: a review of screening criteria over the past 40 years. Bulletin of the World Health Organization. 2008;86(4):317-9.

25. Ioannou L, Delatycki MB, Massie J, Hodgson J, Lewis S. "Suddenly Having two Positive People who are Carriers is a Whole New Thing" - Experiences of Couples Both Identified as Carriers of Cystic Fibrosis Through a Population-Based Carrier Screening Program in Australia. Journal of genetic counseling. 2015;24(6):987-1000.

26. Modra $\amalg$, Massie RJ, Delatycki MB. Ethical considerations in choosing a model for populationbased cystic fibrosis carrier screening. The Medical journal of Australia. 2010;193(3):157-60.

27. Ioannou L, Massie J, Lewis S, McClaren B, Collins V, Delatycki MB. 'No thanks'-reasons why pregnant women declined an offer of cystic fibrosis carrier screening. Journal of community genetics. 2014;5(2):109-17.

28. Mennie ME, Compton ME, Gilfillan A, Liston WA, Pullen I, Whyte DA, et al. Prenatal screening for cystic fibrosis: psychological effects on carriers and their partners. Journal of medical genetics. 1993;30(7):543-8.

29. Rose NC, Wick M. Current recommendations: Screening for Mendelian disorders. Seminars in perinatology. 2016;40(1):23-8.

30. Brennan ML, Schrijver I. Cystic Fibrosis: A Review of Associated Phenotypes, Use of Molecular Diagnostic Approaches, Genetic Characteristics, Progress, and Dilemmas. The Journal of molecular diagnostics : JMD. 2016;18(1):3-14.

31. Caskey CT, Kaback MM, Beaudet AL. The American Society of Human Genetics statement on cystic fibrosis screening. American journal of human genetics. 1990;46(2):393.

32. Brock DJ. Carrier screening for cystic fibrosis. Prenatal diagnosis. 1994;14(13):1243-52.

33. Kerem E, Lynch A. Screening for cystic fibrosis. Ethical and social issues. The American review of respiratory disease. 1991;143(3):457-60.

34. Botkin JR, Alemagno S. Carrier screening for cystic fibrosis: a pilot study of the attitudes of pregnant women. American journal of public health. 1992;82(5):723-5.

35. Loader S, Caldwell P, Kozyra A, Levenkron JC, Boehm CD, Kazazian HH, Jr., et al. Cystic fibrosis carrier population screening in the primary care setting. American journal of human genetics. 1996;59(1):234-47.

36. Schwartz M, Brandt NJ, Skovby F. Screening for carriers of cystic fibrosis among pregnant women: a pilot study. European journal of human genetics : EJHG. 1993;1(3):239-44. 
37. http://www.genet.sickkids.on.ca/ConsortiumDataPage1.html Cystic Fibrosis Genetic Analysis Consortium.

38. Holloway S, Brock DJ. Cascade testing for the identification of carriers of cystic fibrosis. Journal of medical screening. 1994;1(3):159-64.

39. Brock DJ. Carrier screening in the community. Journal of inherited metabolic disease. 1995;18(4):525-32.

40. Benacerraf BR, Chaudhury AK. Echogenic fetal bowel in the third trimester associated with meconium ileus secondary to cystic fibrosis. A case report. The Journal of reproductive medicine. 1989;34(4):299-300.

41. Sepulveda W, Leung KY, Robertson ME, Kay E, Mayall ES, Fisk NM. Prevalence of cystic fibrosis mutations in pregnancies with fetal echogenic bowel. Obstetrics and gynecology. 1996;87(1):103-6.

42. Metcalfe SA. Carrier screening in preconception consultation in primary care. Journal of community genetics. 2012;3(3):193-203.

43. Grody WW, Desnick RJ, Carpenter NJ, Noll WW. Diversity of cystic fibrosis mutation-screening practices. American journal of human genetics. 1998;62(5):1252-4.

44. Grody WW, Cutting GR, Klinger KW, Richards CS, Watson MS, Desnick RJ, et al. Laboratory standards and guidelines for population-based cystic fibrosis carrier screening. Genetics in medicine : official journal of the American College of Medical Genetics. 2001;3(2):149-54.

45. Kiesewetter S, Macek M, Jr., Davis C, Curristin SM, Chu CS, Graham C, et al. A mutation in CFTR produces different phenotypes depending on chromosomal background. Nature genetics. 1993;5(3):274-8.

46. Massie RJ, Poplawski N, Wilcken B, Goldblatt J, Byrnes C, Robertson C. Intron-8 polythymidine sequence in Australasian individuals with CF mutations R117H and R117C. The European respiratory journal. 2001;17(6):1195-200.

47. Watson MS, Cutting GR, Desnick RJ, Driscoll DA, Klinger K, Mennuti M, et al. Cystic fibrosis population carrier screening: 2004 revision of American College of Medical Genetics mutation panel. Genetics in medicine : official journal of the American College of Medical Genetics. 2004;6(5):387-91.

48. Rohlfs EM, Zhou Z, Sugarman EA, Heim RA, Pace RG, Knowles MR, et al. The I148T CFTR allele occurs on multiple haplotypes: a complex allele is associated with cystic fibrosis. Genetics in medicine : official journal of the American College of Medical Genetics. 2002;4(5):319-23.

49. Poulou M, Fylaktou I, Fotoulaki M, Kanavakis E, Tzetis M. Cystic fibrosis genetic counseling difficulties due to the identification of novel mutations in the CFTR gene. Journal of cystic fibrosis : official journal of the European Cystic Fibrosis Society. 2012;11(4):344-8.

50. Delatycki MB, Burke J, Christie L, Collins F, Gabbett M, George P, et al. Human Genetics Society of Australasia position statement: population-based carrier screening for cystic fibrosis. Twin research and human genetics : the official journal of the International Society for Twin Studies. 2014;17(6):578-83.

51. National Consultative Ethics Committee for Health and Life Sciences: Opinion $\mathrm{N}^{\circ} 97$, Ethical issues arising out of the delivery of neonatal genetic information after screening for genetic disorders (the examples of cystic fibrosis and sickle-cell disease) 2007 [

52. Wilson RD, De Bie I, Armour CM, Brown RN, Campagnolo C, Carroll JC, et al. Joint SOGC-CCMG Opinion for Reproductive Genetic Carrier Screening: An Update for All Canadian Providers of 
Maternity and Reproductive Healthcare in the Era of Direct-to-Consumer Testing. Journal of obstetrics and gynaecology Canada : JOGC = Journal d'obstetrique et gynecologie du Canada : JOGC. 2016;38(8):742-62 e3.

53. Sosnay PR, Castellani C, Corey M, Dorfman R, Zielenski J, Karchin R, et al. Evaluation of the disease liability of CFTR variants. Methods in molecular biology. 2011;742:355-72.

54. Castellani C, Cuppens H, Macek M, Jr., Cassiman JJ, Kerem E, Durie P, et al. Consensus on the use and interpretation of cystic fibrosis mutation analysis in clinical practice. Journal of cystic fibrosis : official journal of the European Cystic Fibrosis Society. 2008;7(3):179-96.

55. Grody WW, Thompson BH, Gregg AR, Bean LH, Monaghan KG, Schneider A, et al. ACMG position statement on prenatal/preconception expanded carrier screening. Genetics in medicine : official journal of the American College of Medical Genetics. 2013;15(6):482-3.

56. Nazareth SB, Lazarin GA, Goldberg JD. Changing trends in carrier screening for genetic disease in the United States. Prenatal diagnosis. 2015;35(10):931-5.

57. Beaudet AL. Global genetic carrier testing: a vision for the future. Genome medicine. 2015;7(1):79.

58. Lindheim SR, Jaeger AS. Expanded preconception carrier screening in clinical practice: cutting the Gordian Knot. Fertility and sterility. 2015;104(2):281-2.

59. Edwards JG, Feldman G, Goldberg J, Gregg AR, Norton ME, Rose NC, et al. Expanded carrier screening in reproductive medicine-points to consider: a joint statement of the American College of Medical Genetics and Genomics, American College of Obstetricians and Gynecologists, National Society of Genetic Counselors, Perinatal Quality Foundation, and Society for Maternal-Fetal Medicine. Obstetrics and gynecology. 2015;125(3):653-62.

60. Richards S, Aziz N, Bale S, Bick D, Das S, Gastier-Foster J, et al. Standards and guidelines for the interpretation of sequence variants: a joint consensus recommendation of the American College of Medical Genetics and Genomics and the Association for Molecular Pathology. Genetics in medicine : official journal of the American College of Medical Genetics. 2015;17(5):405-24.

61. Lim RM, Silver AJ, Silver MJ, Borroto C, Spurrier B, Petrossian TC, et al. Targeted mutation screening panels expose systematic population bias in detection of cystic fibrosis risk. Genetics in medicine : official journal of the American College of Medical Genetics. 2016;18(2):174-9.

62. Sosnay PR, Castellani C, Penland CM, Rommens JM, Lewis M, Raraigh KS, et al. Bias in CFTR screening panels. Genetics in medicine : official journal of the American College of Medical Genetics. 2016;18(2):209.

63. Lucarelli M, Porcaro L, Biffignandi A, Costantino L, Giannone V, Alberti L, et al. A New Targeted CFTR Mutation Panel Based on Next-Generation Sequencing Technology. The Journal of molecular diagnostics : JMD. 2017.

64. Zvereff VV, Faruki H, Edwards M, Friedman KJ. Cystic fibrosis carrier screening in a North American population. Genetics in medicine : official journal of the American College of Medical Genetics. 2014;16(7):539-46.

65. Wei $\mathrm{S}$, Quigg MH, Monaghan KG. Is cystic fibrosis carrier screening cost effective? Community genetics. 2007;10(2):103-9.

66. Lieu TA, Watson SE, Washington AE. The cost-effectiveness of prenatal carrier screening for cystic fibrosis. Obstetrics and gynecology. 1994;84(6):903-12. 
67. Vintzileos AM, Ananth CV, Smulian JC, Fisher AJ, Day-Salvatore D, Beazoglou T. A costeffectiveness analysis of prenatal carrier screening for cystic fibrosis. Obstetrics and gynecology. 1998;91(4):529-34.

68. Maxwell S, Brameld K, Youngs L, Geelhoed E, O'Leary P. Informing policy for the Australian context - Costs, outcomes and cost savings of prenatal carrier screening for cystic fibrosis. The Australian \& New Zealand journal of obstetrics \& gynaecology. 2010;50(1):51-9.

69. Radhakrishnan M, van Gool K, Hall J, Delatycki M, Massie J. Economic evaluation of cystic fibrosis screening: a review of the literature. Health policy. 2008;85(2):133-47.

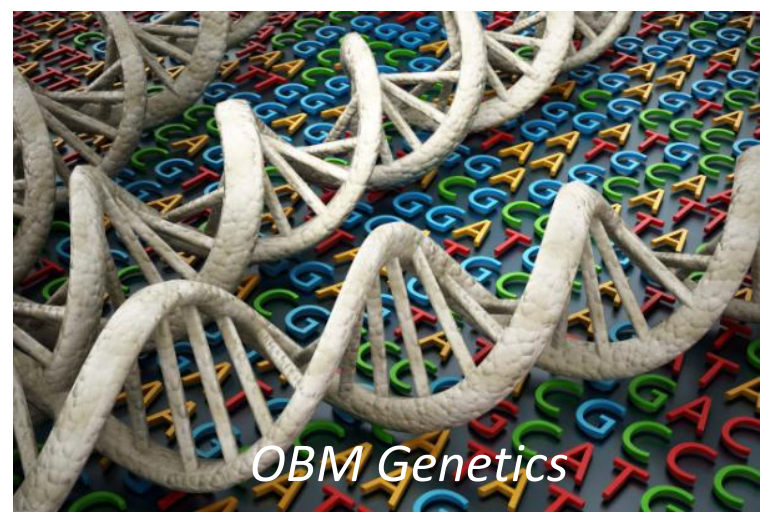

Enjoy OBM Genetics by:

1. Submitting a manuscript

2. Joining in volunteer reviewer bank

3. Joining Editorial Board

4. Guest editing a special issue

For more details, please visit:

http://www.lidsen.com/journals/genetics 